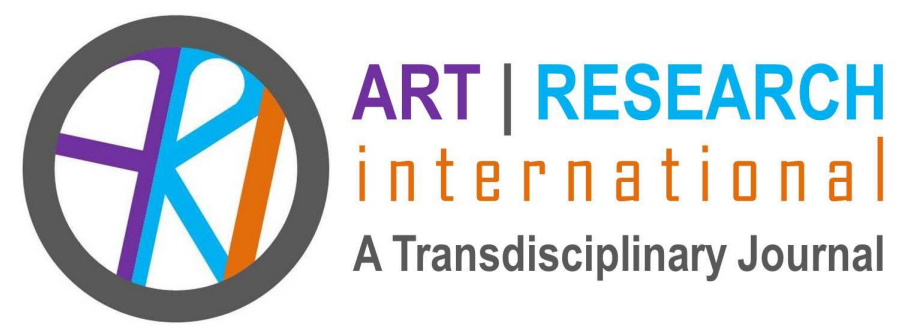

\title{
AN EKPHRASTIC REVIEW OF ILONA PAPPNE DEMECS AND EVONNE MILLER'S “WOVEN NARRATIVES: A CRAFT ENCOUNTER WITH TAPESTRY WEAVING IN A RESIDENTIAL AGES CARE FACILITY"'
}

\section{Adrian Schoone Auckland University of Technology adrian.schoone@aut.ac.nz}

Adrian Schoone is a senior lecturer in Education. Through poetic inquiry approaches, Adrian researches in the areas of alternative and inclusive education. In 2015, Adrian completed New Zealand's first poetic inquiry-based PhD in Education.

Abstract: The visual poem, "The loom," is an ekphrastic response to llona Pappne Demecs and Evonne Miller's article "Woven Narratives: A Craft Encounter with Tapestry Weaving in a Residential Ages Care Facility." By drawing words and phrases from Demec's article, the author wove a word tapestry, in a technique learnt from a child in a South Auckland primary school in New Zealand.

Keywords: visual poetry; found poetry; intergenerational; ekphrasis 
The phrase "woven narratives" evoked a memory of this concept when I was teaching found poetry to a primary classroom in South Auckland, New Zealand. I had instructed the class of lively students to choose a book from the library corner, to read the book carefully and then copy down words and phrases that somehow resonated with them. Perhaps these were unusual words, perhaps the words stimulated an emotional response, or perhaps they sounded fun to say on the tongue. After the students refined their list of words, I instructed them to cut out each word or phrase and paste these in a list formation on a poster-sized chart. Most students dutifully glued the words this way. One student however, placed his words in a woven-type pattern on the paper, like the poem I have created here. His woven narrative opened numerous possibilities for reading the text (for example, up-and-down, down the diagonal lines, read around the boxes, read each parallel line downwards left and right). Each way of reading opened the text to discover multiple interpretations, resonances and surprises. Inadvertently, the student reflected Bollobás' (1986) charge to poets, not to "master or control language (and force it into linear progression), but to participate in this performance where spatial configurations are born" (p. 285). Similar to this student, I also created a woven narrative poem from words and phrases I found in Ilona Pappne Demecs and Evonne Miller's (2019) article "Woven Narratives: A Craft Encounter with Tapestry Weaving in a Residential Ages Care Facility." My aim was to weave the text in order to poetically re/present content and to create new encounters.

In writing this review, I am mindful of the generational nexus created between the woven narrative I learnt from a primary school student in South Auckland, New Zealand, and the woven narratives created by the residents of an aged care facility. This rich study on residents' encounter with "a rare craft," led me to consider in what spaces the narratives created through the Tapestry of Home could be shared across generations, and in what ways the narratives between generations and cultures, could be woven into a unified tapestry of home. This would be a hopeful gesture in a world that builds walls between nations, between cultures and between age groups. 


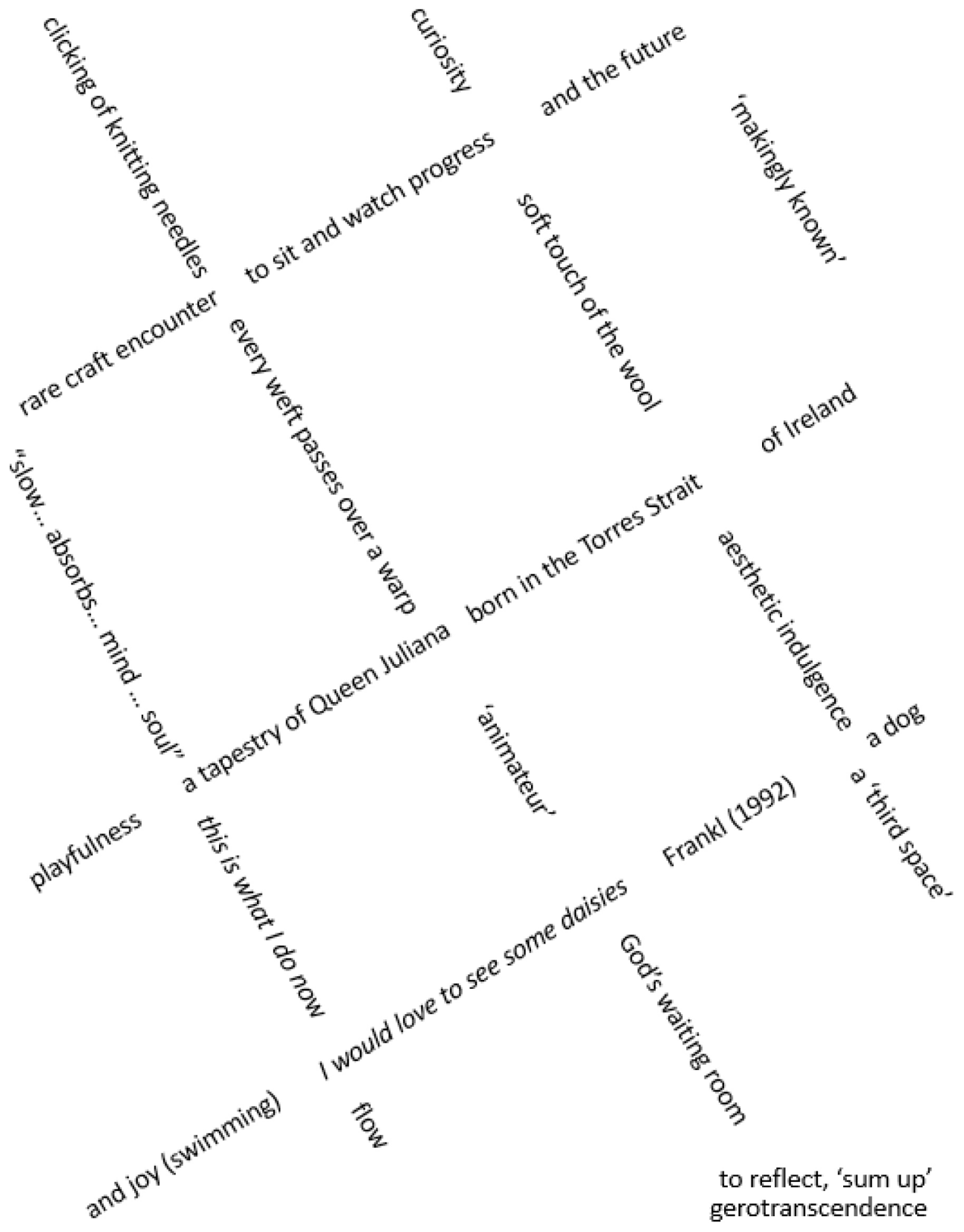

Figure 1. The loom $(1.8 \mathrm{~m} \times 2 \mathrm{~m})$ 


\section{REFERENCES}

Bollobás, E. (1986). Poetry of visual enactment: The concrete poem. Word \& Image, 2(3), 279-285.

Pappne Demecs, I., \& Miller, E. (2019). Woven narratives: A craft encounter with tapestry weaving in a residential aged care facility. Art/Research International: $A$ Transdisciplinary Journal (4)1, 256-286. 